\title{
Assessment of Temperament and Character Profile with Anxiety and Depression in Patients with Acne
}

\author{
Perihan Öztürk' ${ }^{1}$ Fatma Özlem Orhan², Ali Özer ${ }^{3}$, Tuğba Karakaş${ }^{1}$, Ali Nuri Öksüz² Nur Yalçın Yetişir² \\ ${ }^{1}$ Department of Dermatology, Kahramanmaraş Sütçü Imam University Faculty of Medicine, Kahramanmaraş, Turkey \\ ${ }^{2}$ Department of Psychiatry, Kahramanmaraş Sütçü İmam University Faculty of Medicine, Kahramanmaraş, Turkey \\ ${ }^{3}$ Department of Public Health, Inönü University Faculty of Medicine, Malatya, Turkey
}

\begin{abstract}
Background: Acne is the most common skin disease, affecting nearly $85 \%$ of the population as well as their lives. Acne can severely affect social and psychological functioning. Patients with acne may have anxiety, depression, decreased self-esteem, interpersonal difficulties, unemployment, social withdrawal, and even suicidal intent.

Aims: The aim of this study was to evaluate the temperament and character inventory (TCl) of patients with acne and to compare the results with those of healthy controls.

Study Design: Case-control study

Methods: The study population consisted of 47 patients with acne, and 40 healthy control subjects. All participants were instructed to complete a selfadministered 240-item TCl and the Hospital Anxiety and Depression Scale.

Results: In this study, the scores for the temperament properties Worry and pessimism (HA1) and Dependence (RD4) and the character properties Social acceptance (C1) and Integrated conscience (C5) were found to be higher in acne patients than in healthy controls $(p<0.05)$. Compared to the controls, depression and anxiety scores were found to be markedly higher in the patients with acne. Acne type correlated positively with the Disorderliness (NS4) subscale of Novelty seeking (NS) and anxiety. Additionally, acne type correlated negatively with the Attachment (RD3) subscale of Reward Dependence (RD), with the Transpersonal identification (ST2) and Spiritual acceptance (ST3) subscales of Self-Trancendence (ST), and with the Compassion (C4) subscale of Cooperativeness (C).
\end{abstract}

Conclusion: Studies in this area may lead to the development of specific and focused interventions for $\mathrm{TCl}$ in patients with acne vulgaris. We suggest that the evaluation and treatment of acne should also include psychosomatic approaches in clinical practice.

Key Words: Acne, anxiety, depression, temperament, character

Received: 13.08 .2012

Accepted: 15.10.2012

\section{Introduction}

Acne is a chronic inflammatory disease of the pilosebaceous unit; this dermatological disorder is very common among teenagers and young adults (1). Acne is an important milestone in the development of personality, which manifests itself in adolescence when physical appearance and self-image are thought to be almost the equivalent of self-esteem; therefore, acne may have a role in the negative construction of individual identity. Decreased self-esteem, emotions such as anxiety and depression may reflect interpersonal relationships negatively (2). This negativity may cause inappropriate behaviour during a person's daily life when struggling and could leave persistent problems in personality structure. Although acne is a common disease, there have been no clinical studies investigating the temperament and characteristics of patients. However, after the clinical experiences it is understood that face-seated nodulocystic acne could affect the external appearance negatively; painful and bleeding lesions on the trunk could also be a problem. Rubinow et al. (3) de- termined that patients with cystic acne had complaints such as embarrassment, shyness, nervousness, social isolation, decreased self-image and physical activity, avoidance of the opposite sex and difficulty in sleeping.

The temperament and character inventory $(\mathrm{TCl})$ provides a psychobiological model of personality that has the potential to provide insight into human personality at multiple levels of analysis (4). According to Cloninger's (5) psychobiological model, personality has four temperament (novelty seeking (NS), harm avoidance (HA), reward dependence (RD), and persistence (P)) and three character (self-directedness (SD), cooperativeness (C), and selftranscendence (ST)) dimensions. Cloninger defines temperament as the components of personality that are mildly heritable, developmentally stable, emotion-based, and not influenced by socio-cultural learning. Character traits are a reflection of personal goals and values specified in terms of "subject-object" relations, are moderately influenced by socio-cultural learning, and mature progressively throughout life (5). There were no traits considered regarding 
working temperament and character when exploring the literature of patients with acne.

The aim of the presented study was to examine whether patients with acne have common specific personality traits (as evaluated by the $\mathrm{TCl}$ self-report questionnaire) and if there is any relationship between the $\mathrm{TCl}$ scores and depression and anxiety.

\section{Material and Methods}

Forty healthy volunteers and 47 patients with acne, who were referred to our dermatology outpatient clinic between the January-December 2011, were included in the study.

\section{Inclusion criteria for patients}

Patients were over the age of 18 , diagnosed with acne, literate, did not have any systemic or metabolic diseases, had no dermatological diseases other than acne, and an absence of dementia, mental retardation, cognitive impairment, the presence of recurrent suicidal thoughts, psychotic illness, psychiatric drug-use, advanced neurological diseases and decompensated systemic diseases. Primarily, patients with acne who visited our dermatology clinic were informed about the study and were asked whether they agreed to participate. Following examination, the doctor decided if the patients who agreed to participate in the study befit the study criteria. Patients who do not meet the criteria were not included in the study. After examination in the dermatology clinic, patients diagnosed with acne vulgaris and who chose to participate in the study were assessed, and the following demographics were noted: age, gender, education level, marital status and duration of acne; routine blood chemistries (glucose, urea, creatinine, ALT, AST) and hormone tests (FSH, LH, oestrogen, progesterone, free testosterone, DHESO4, prolactin) were done. Patients who had abnormalities in these tests were not included in the study. According to the type of acne, patients were divided into three groups: mild (mainly comedones), moderate (in addition to comedones, papules and pustules mainly) and severe (comedones, papules, pustules, nodules and cystic lesions in addition). According to the localisation, patients were divided into two groups: face involvement and face and body involvement. 47 patients who complied with the criteria were included in the study. For the diagnosis of the patients, SCID I (Structured Clinical Interview for DSM-IV) criteria, developed from the DSM-IV criteria, were used.

For the control group, volunteers who were not diagnosed with acne vulgaris or any systemic, metabolic or psychiatric illness were included. After recording the sociodemographic characteristics of patients and the control group, the Hospital Anxiety and Depression Scale (HAD) and TCl were applied.

\section{Ethical Considerations}

This study was approved by the ethics committee of Kahramanmaraş Sütçüimam University School of Medicine and conducted according to the ethical standards of the Helsinki Declaration of 2000. All subjects signed a written informed consent.

\section{Measures}

Temperament and Character Inventory (TCI): This selfreported scale consists of 240 items with "true" or "false" as the response options; it can be applied to individuals aged 18 years old or older. The $\mathrm{TCl}$ consists of seven main scales formed by four dimensions of temperament (NS, HA, RD and $\mathrm{P})$ and 3 dimensions of character (SD, C and ST), along with 24 subscales of these scales. It has been commonly used in different areas of psychological and psychiatric research and practice in the last 10 years. The $\mathrm{TCl}$ was developed by Cloninger (5) and the Turkish version of the $\mathrm{TCl}$ has been validated by Kose et al. $(6,7)$.

The Hospital Anxiety and Depression Scale: The HAD Scale is a self-reported questionnaire for hospital out-patients in medical or surgical departments used to assess anxiety and depression as two dimensions (8). The score for each subscale ranges from zero to 21: the higher the score, the worse the status, with respect to that particular category (9). The validation and reliability studies of the HAD Scale developed by Zigmond and Snaith (1983), were carried out by Aydemir et al. (10). The HAD scale has been prepared to screen for anxiety and depression in patients with physical disease, and contains anxiety and depression subscales. The cut-off points in the Turkish version of the scale are 10 for the anxiety subscale and 7 for the depression subscale.

\section{Statistical analyses}

Data were computerised using the Statistical Packages for the Social Sciences (SPSS v.15.0; SPSS Inc., Chicago, IL, USA). The data were not normally distributed according to the Kolmogorov-Smirnov test $(p<0.05)$. The Man Whitney U-test, chisquare test and spearman correlation were used in statistical analysis. Values are presented as Minimum-Median-Maximum and as percentages. A $p$ value $<0.05$ was considered statistically significant.

\section{Results}

The min-median-max of 47 acne patients, and the control group were 16-20-26 years, and 17-24-47 years, respectively $(p<0.05)$. In the study group, $8(17 \%)$ of the patients were male, and 39 (83\%) were female. In the control group, $33(82.5 \%)$ of volunteers were female and 7 (17.5\%) were male $(p>0.05)$. Marital status, education level and occupation of the patient and control group were compared; no statistically significant differences were detected ( $p>0.05)$.

The average duration of acne among patients was found to be $1-3-10$ years. Eight (48.9\%) of the patients had mild lesions, $25(53.2 \%)$ had moderate and 14 (29.8\%) of the patients had severe lesions. Also, 23 (48.9\%) of the patients with acne had lesions located on the face, while 24 (51.1\%) of the patients had lesions were located on both the face and body.

The sociodemographic characteristics of patients with acne and the control group are shown in Table 1.

In this study, the scores for temperament properties (HA) Worry and pessimism (HA1) and Dependence (RD4) and the character properties Social acceptance (C1) and Integrated conscience (C5) were found to be higher in acne patients than 
Table 1. Socio-demographic variables of patients and controls

\begin{tabular}{|lccc|}
\hline & $\begin{array}{c}\text { Acne } \\
\mathbf{n = 4 7}(\%)\end{array}$ & $\begin{array}{c}\text { Control } \\
\mathbf{n = 4 0}(\%)\end{array}$ & $\mathbf{p}$ \\
\hline Sex & & & 0.38 \\
Female & $39(83)$ & $33(82.5)$ & \\
Male & $8(17)$ & $7(17.5)$ & \\
\hline Occupation & & & 0.49 \\
Worker & $4(8.5 \%)$ & $2(5 \%)$ & \\
Jobless & $1(2.1 \%)$ & $2(5 \%)$ & \\
Housewife & $4(8.5 \%)$ & $2(5 \%)$ & \\
Student & $38(80.8 \%)$ & $32(80 \%)$ & \\
Education & & & \\
Primary & $15(29.8 \%)$ & $10(25 \%)$ & \\
High school & $20(42.6 \%)$ & $16(40 \%)$ & \\
University & $12(25.5 \%)$ & $14(35 \%)$ & \\
\hline Age min, m, max & $16-20-26$ & $17-24-47$ & 0.00 \\
\hline Min, m, max: minimum, median, maximum & \\
\hline
\end{tabular}

in healthy controls $(p<0.05)$. There was no significant change in the other scales ( $p>0.05$ ) (Table 2).

Depression and anxiety scores were significantly higher in patients with acne compared to the control group $(p<0.05)$ (Table 3). As a result of the SCID, depression was found in 11 patients, anxiety in one patient, and generalised anxiety and depression in four patients; however, 31 patients revealed no pathology.

As shown in Table 4, acne type correlated positively with the Disorderliness (NS4) subscale of NS and anxiety. Additionally, acne type correlated negatively with the Attachment (RD3) subscale of RD, the Transpersonal identification (ST2) and Spiritual acceptance (ST3) subscales of ST, and the Compassion (C4) subscale of $C$. There was no correlation between acne duration and $\mathrm{TCl}$ scores. Anxiety and depression correlated positively with HA, HA1 and Shyness (HA3) subscales of $\mathrm{HA}$, and correlated negatively with Exploration (NS1), Attachment (RD3), RD, P, Responsibility (S1), Purposefulness (S2), Resourcefulness (S3), Enlightened $2^{\text {nd }}$ nature (S5), and ST.

\section{Discussion}

There is no precise information about whether there is a relationship between personality and the development of acne (11). Some authors suggest that people with acne have unstable, neurotic traits such as avoidant personality traits; however, other authors have suggested that acne should be treated as an organic event and that personality traits have no effect on the development of acne $(12,13)$.

Several studies of depression and social anxiety assessment have been conducted in patients with acne (14-16). Anxiety may be worsened if there is lack of response to acne treatment. Clinically, both mild and moderate acne can be associated with significant depression and suicidal ideation, which would require psychiatric intervention (17).
Table 2. Comparison of the temperament and character subdimensions in acne patients, and healthy controls

\begin{tabular}{|c|c|c|c|}
\hline \multirow[t]{2}{*}{ TCl sub-headings } & $\begin{array}{l}\text { Acne } \\
\text { group } \\
(n=47)\end{array}$ & $\begin{array}{l}\text { Control } \\
\text { group } \\
(n=40)\end{array}$ & \multirow[t]{2}{*}{ p* } \\
\hline & \multicolumn{2}{|c|}{ Min,m,max Min,m,max } & \\
\hline \multicolumn{4}{|l|}{ Novelty seeking (NS) } \\
\hline NS1 (Exploration) & $3-6-27$ & $3-7-9$ & 0.10 \\
\hline NS2 (Impulsiveness) & $1-4-8$ & $1-4,5-8$ & 0.22 \\
\hline NS3 (Extravagance) & $1-4-8$ & $2-5-8$ & 0.13 \\
\hline NS4 (Disorderliness) & $1-4-28$ & $2-5-16$ & 0.32 \\
\hline NS (Total) & $12-19-47$ & $16-21-29$ & 0.15 \\
\hline \multicolumn{4}{|l|}{ Harm Avoidance (HA) } \\
\hline HA1 ( Worry and pessimism) & $1-6-11$ & $3-5-8$ & 0.02 \\
\hline HA2 (Fear of uncertainty) & $0-4-16$ & $1-4-7$ & 0.22 \\
\hline HA3 (Shyness) & $0-4-8$ & $1-4-6$ & 0.30 \\
\hline HA4 (Fatiguability) & $0-4-8$ & $1-4.5-8$ & 0.35 \\
\hline HA (Total) & $3-18-32$ & $9-17.5-22$ & 0.04 \\
\hline \multicolumn{4}{|l|}{ Reward Dependence (RD) } \\
\hline RD1 (Sentimentality) & $1-7-26$ & $4-7,5-9$ & 0.48 \\
\hline RD3 (Attachment) & $1-4-25$ & $1-4-8$ & 0.17 \\
\hline RD4 (Dependence) & $0-6-11$ & $0-2-4$ & 0.04 \\
\hline RD (Total) & $8-13-34$ & $9-13-20$ & 0.66 \\
\hline \multicolumn{4}{|l|}{ Persistence $(P)$} \\
\hline$P$ & $1-4-8$ & $0-5-7$ & 0.60 \\
\hline \multicolumn{4}{|l|}{ Self-Directedness (SD) } \\
\hline S1 (Responsibility) & $0-5-14$ & $1-3-7$ & 0.54 \\
\hline S2 (Purposefulness) & $2-5-8$ & $2-5-7$ & 0.29 \\
\hline S3 (Resourcefulness) & $0-3-5$ & $0-3-5$ & 0.74 \\
\hline S4 (Self-acceptance) & $1-5-10$ & $2-5-10$ & 0.91 \\
\hline S5 (Enlightened 2 ${ }^{\text {nd }}$ nature) & 3-8-12 & $4-7.5-12$ & 0.39 \\
\hline $\mathrm{S}$ (Total) & $11-27-39$ & $12-25.5-34$ & 0.28 \\
\hline \multicolumn{4}{|l|}{ Cooperativeness $(\mathrm{C})$} \\
\hline C1 (Social acceptance) & $2-6-14$ & $1-4-8$ & 0.003 \\
\hline C2 (Empathy) & $1-4-7$ & $2-4-6$ & 0.25 \\
\hline C3 (Helpfulness) & $2-4-7$ & $2-5-7$ & 0.06 \\
\hline C4 (Compassion) & $0-7-10$ & $3-6,5-10$ & 0.09 \\
\hline C5 (Integrated conscience) & 3-6-9 & $3-5-9$ & 0.003 \\
\hline C (Total) & $17-28-39$ & $20-36-24.5$ & 0.08 \\
\hline \multicolumn{4}{|l|}{ Self-Transcendence (ST) } \\
\hline ST1 (Self-forgetfulness) & $1-6-11$ & $4-6,5-9$ & 0.36 \\
\hline ST2 (Transpersonal identification) & $1-5-9$ & $3-6-8$ & 0.09 \\
\hline ST3 (Spiritual acceptance) & $1-8-13$ & $3-8-11$ & 0.69 \\
\hline ST (Total) & $7-18-28$ & $13-20-26$ & 0.32 \\
\hline
\end{tabular}

$p^{\star}$ : $p$-values for comparison between patients and controls with Mann-Whitney Test.

Min, $\mathrm{m}$, max: minimum, median, maximum 
Table 3. Comparison of average HAD scores between acne patients and healthy controls

\begin{tabular}{|cccc|}
\hline & $\begin{array}{c}\text { Acne } \\
\mathbf{n = 4 7}(\%)\end{array}$ & $\begin{array}{c}\text { Control } \\
\mathbf{n = 4 0}(\%)\end{array}$ & $\mathbf{p}$ \\
\hline HAD-A & $1-10-17$ & $2-7-15$ & 0.001 \\
HAD-D & $1-5-17$ & $1-3-11$ & $<0.001$ \\
\hline
\end{tabular}

HAD-A: The Hospital Anxiety and Depression-Anxiety

HAD-D: The Hospital Anxiety and Depression-Depression

Table 4. Correlation of anxiety, depression and acne type with $\mathrm{TCl}$ scores

\begin{tabular}{|c|c|c|c|c|}
\hline & $\begin{array}{c}\text { Statistical } \\
\text { values }\end{array}$ & $\begin{array}{l}\text { Acne } \\
\text { type }\end{array}$ & Depression & Anxiety \\
\hline NS1 & $\mathrm{p}$ & 0.485 & 0.005 & 0.001 \\
\hline (Exploration) & r & -0.104 & -0.302 & -0.364 \\
\hline NS4 & $\mathrm{p}$ & 0.015 & 0.704 & 0.112 \\
\hline (Disorderliness) & $r$ & 0.353 & 0.041 & 0.171 \\
\hline HA1 & $\mathrm{p}$ & 0.176 & 0.049 & 0.002 \\
\hline (Worry and pessimism) & $r$ & 0.238 & 0.212 & 0.325 \\
\hline HA3 & $P$ & 0.361 & 0.002 & 0.001 \\
\hline (Shyness) & $r$ & 0.136 & 0.326 & 0.337 \\
\hline HAT & $p$ & 0.555 & 0.031 & 0.007 \\
\hline (Harm Avoidance total) & $r$ & 0.088 & 0.231 & 0.286 \\
\hline RD3 & $p$ & 0.001 & 0.049 & 0.002 \\
\hline (Attachment) & r & -0.450 & -0.212 & -0.334 \\
\hline RDT & $p$ & 0.011 & 0.409 & 0.019 \\
\hline (Reward Dependence Tota & tal) $r$ & -0.367 & -0.090 & -0.252 \\
\hline$p$ & $\mathrm{p}$ & 0.084 & 0.010 & 0.013 \\
\hline (Persistence) & $r$ & -0.255 & -0.276 & -0.266 \\
\hline S2 & $\mathrm{p}$ & 0.008 & 0.199 & 0.006 \\
\hline (Purposefulness) & r & -0.382 & -0.139 & -0.294 \\
\hline S3 & $p$ & 0.037 & 0.746 & 0.007 \\
\hline (Resourcefulness) & r & 0.470 & -0.035 & -0.28 \\
\hline ST & $p$ & 0.016 & 0.080 & 0.00 \\
\hline (Self-Transcendence) & $r$ & -0.350 & 0.320 & -0.385 \\
\hline C4 & $\mathrm{p}$ & 0.030 & 0.115 & 0.851 \\
\hline (Compassion) & $r$ & -0.318 & 0.170 & 0.020 \\
\hline CT & $p$ & 0.038 & 0.794 & 0.181 \\
\hline (Cooperativeness) & $r$ & -0.304 & 0.028 & -0.145 \\
\hline \multirow[t]{2}{*}{ Anxiety } & $\mathrm{p}$ & 0.019 & 0.000 & \\
\hline & $r$ & 0.341 & 0.551 & 1.000 \\
\hline \multirow[t]{2}{*}{ Depression } & $p$ & 0.680 & & 0.000 \\
\hline & $r$ & 0.062 & 1.000 & 0.551 \\
\hline
\end{tabular}

$p^{*}$ : p-values for comparison between patients and controls with Mann-Whitney Test. $j$

Min, $m$, max: minimum, median, maximum
Gupta et al. (18) and Fried et al. $(19,20)$ found both depression and suicidal tendencies in patients with acne. Baz et al. (21) investigated the impact of isotretinoin therapy on quality of life and anxiety-depression in patients with severe acne; for this purpose, the DLQI and HAD (Hospital Anxiety and Depression) scales were applied. In the patient group, a significant change was not detected in HAD scores after treatment. Ozcan et al. (22) and Kellett et al. (23) could not find any statistically significant association between acne and depression-anxiety, when compared with the control groups. In our study, similar to some of the previous studies, we detected that anxiety and depression scores were significantly higher among patients than the control group. These contradictory results indicate that more data in this area are required and there is a need to consider other variables that could play a role.

There are only a few studies that have investigated personality traits in dermatological diseases (24). In order to understand the relationship between acne and personality, using $\mathrm{TCl}$ in studies, which allows the evaluation of temperament and character in a psychobiological model, plays a major role $(24,25)$. Cloninger's psychobiological personality model has been widely used recently and allows this requirement to be approached.

In our study, scores of anxiety, depression, HA, HA1, RD4, $\mathrm{C} 1$ and $\mathrm{C} 5$ were higher among patients with acne than in the control group.

Individuals with high HA scores tend to be cautious, careful, fearful, tense, nervous, doubtful, passive, negativistic, insecure, or pessimistic, even in situations that do not worry other people (26). They also tend to be inhibited and shy in social situations (27). People with high HA respond to stressful events with a higher proportion of depressive symptoms and expect a dangerous situation even in the absence of danger $(5,25)$. High HA scores were related with depression and anxiety symptoms. Consistent with our results, several previous studies have shown higher scores for HA in patients with depression and anxiety (28-32). In our study, there was a significant correlation between HA and anxiety and depression, and our results suggest that high HA scores constitute a high risk for both depression and acne. In addition, the high scores of HA with acne also suggest that these patients have a general temperament that, as a response to stress, leaves the patient prone to developing acne. In addition, HA may be a personality trait that is specific to patients with acne.

$\mathrm{RD}$ (the third temperament component in TCl) reflects behaviour response, which stimulates a social reward and reflects a genetic tendency that stimulates the continuation of this behaviour $(5,25)$. In the present study, the scores for RD subscale RD4 were higher among patients with acne than in the control group. Significantly higher RD scores in patients with acne may be due to placing more importance on social consent, being susceptible or easily impressionable by others or wanting to be perfect in the eyes to others. Although depression is also associated with lower RD scores, high RD scores may be considered a personality trait for patients with acne (as well as skin diseases such as psoriasis). 
Cooperativeness refers to social acceptance, empathy, helpfulness, compassion, and pure-hearted principles. Individuals with a high level of $C$ are described as reasonable, compassionate, empathetic, helpful, and principled $(5,25)$. As shown in many previous studies, as well as in our study, depression and anxiety scores showed a negative correlation with $\mathrm{C}$. In our study, the negative correlation seen between increasing severity of acne and $\mathrm{C}$ may be interpreted as a worsening of the person's external appearance, which may cause social intolerance and an increased susceptibility to depression.

When interpreting our results, it is important to note some limitations of our study. First, our sample size was relatively small; hence, it may not be representative of all acne patients. Further studies are required to confirm these results in larger clinical samples. We can draw no conclusions about cause-and-effect relationships because of the cross-sectional nature of the data.

Finally, we used self-reported questionnaires to evaluate psychiatric symptoms; clinician-administered structured interviews and scales could yield more reliable findings. In conclusion, this study suggests that acne patients have distinctive temperament dimensions compared to healthy controls. Further studies are needed to determine the relationship between patterns of temperament and character dimensions and acne, including following successful treatment and longitudinal courses of patients. As with other psychosomatic disorders, in acne vulgaris, it will be incomplete to examine only the psychiatric condition and personality characteristics. Within the framework of a multifactorial disease model, environmental and emotional issues add to the genetic and characteristic floor, which can lead to increased sebum and can be considered to cause and aggravate acne.

In addition to the role of psychological factors during the start, aggravation and healing of disease, disorders that affect body image have important affects on temperament and character. It is important to approach the disease according to the biopsycosocial-medical model within the framework and to plan the treatment by considering this.

Ethics Committee Approval: Ethics committee approval was received for this study from the ethics committee of Kahramanmaraş Sütçü Imam University School of Medicine.

Informed Consent: Written informed consent was obtained from patients who participated in this study.

Peer-review: Externally peer-reviewed.

Author contributions: Concept - P.Ö., F.Ö.O.; Design - P.Ö., F.Ö.O.; Supervision - P.Ö., F.Ö.O.; Resource - T.K., A.N.Ö., N.Y.Y.; Materials - T.K., A.N.Ö., N.Y.Y.; Data Collection\&/or Processing - T.K., A.N.Ö., N.Y.Y.; Analysis\&/or Interpretation - A.Ö.; Literature Search - P.Ö.; Writing - P.Ö.; Critical Reviews - P.Ö., F.Ö.O.

Conflict of Interest: No conflict of interest was declared by the authors.

Financial Disclosure: No financial disclosure was declared by the authors.

\section{References}

1. Demirçay Z, Senol A, Seckin D, Demir F. Reliability of Turkish version of acne quality of life scale in patients with acne vulgaris. Türkderm 2006;40:94-7.
2. Rapp DA, Brenes GA, Feldman SR, Fleischer AB Jr, Graham GF, Dailey $M$, et al. Anger and acne: implications for quality of life, patient satisfaction and clinical care. Br J Dermatol 2004;151: 183-9. [CrossRef]

3. Rubinow DR, Peck GL, Squillace KM, Gantt GG. Reduced anxiety and depression in cystic acne patients after successful treatment with oral isotretinoin. J Am Acad Dermatol 1987;17:25-32. [CrossRef]

4. Dzamonja-Ignjatovic T, Svrakic DM, Svrakic N, Jovanovic MD, Cloninger RC. Cross-cultural validation of the revised Temperament and Character Inventory: Serbian data. Compr Psychiatry 2010;51:649-55. [CrossRef]

5. Cloninger CR, Svrakic DM, Przybeck TR. A psychobiological model of temperament and character. Arch Gen Psychiatry 1993;50:975-90. [CrossRef]

6. Kose S, Sayar K, Kalelioglu U, et al. The Turkish version of the TCl: reliability, validity, and factorial structure. Bulletin Clinical Psychopharmacology 2004;14:107-31.

7. Kose S, Sayar K, Kalelioglu U, Aydin N, Celikel FC, Gulec H, et al. Normative data and factorial structure of the Turkish version of the Temperament and Character Inventory (TCl). Compr Psychiatry 2009;50:361-8. [CrossRef]

8. Aydemir O. Validity and Reliability of Turkish Version of Hospital Anxiety and Depression Scale. Turkish J Psychiatry 1997;8:280-7.

9. Zigmond AS, Snaith RP. The hospital anxiety and depression scale. Acta Psychiatr Scand 1983;67:361-70. [CrossRef]

10. Aydemir O, Guvenir T, Kuey L. Turkish version of hospital anxiety and depression scale. Turkish J Psychiatry 1997;8:280-7.

11. Jones-Caballero M, Chren MM, Soler B, Pedrosa E, Peñas PF. Quality of life in mild to moderate acne: relationship to clinical severity and factors influencing change with treatment. J Eur Acad Dermatol Venereol 2007;21:219-26. [CrossRef]

12. John KOO. Psychodermatology: A practical manual for clinicians. Curr Probl Dermatol 1995;7:204-32. [CrossRef]

13. Lim CC, Tan TC. Personality, disability and acne in college students. Clin Exp Dermatol 1991;16:371-3. [CrossRef]

14. Finlay AY. Quality of life measurement in dermatology: a practical guide. Br J Dermatol 1997;136:305-14. [CrossRef]

15. Klassen AF, Newton JN, Mallon E. Measuring quality of life in people referred for specialist care of acne: comparing generic and diseasespesific measures. J Am Acad Dermatol 2000;43:229-33. [CrossRef]

16. Takahashi N, Suzukamo Y, Nakamura M, Miyachi Y, Green J, Ohya $Y$, et al. Japanese version of the Dermatology Life Quality Index: validity and reliability in patients with acne. Health Qual Life Outcomes 2006;4:46-52. [CrossRef]

17. Thomas DR. Psychosocial effects of acne. J Cutan Med Surg 2005;4:3-5. [CrossRef]

18. Gupta MA, Gupta AK. Depression and suicidal ideation in dermatology patients with acne, alopecia areata, atopic dermatitis and psoriasis. Br J Dermatol 1998;139:846-50. [CrossRef]

19. Fried RG, Gupta MA, Gupta AK. Depression and skin disease. Dermatol Clin 2005;23:657-64. [CrossRef]

20. Fried RG, Wechsler A. Psychological problems in the acne patient. Dermatol Ther 2006;19:237-40. [CrossRef]

21. Baz K, Yazıcı K, Köktürk A, et al. Effects of isotretinoin treatment on dermatological quality of life and anxiety/depression inpatients with severe acne. T Klin J Dermatol 2004;14:75-9.

22. Ozcan Y, Ozcan H, Unal S. Personality Characteristics in Patients with Acne Vulgaris. Klinik Psikiatri 2000;3:56-60.

23. Kellett SC, Gawkrodker DJ. The psychological and emotional impact of acne and the effect of treatment with isotretinoin. $\mathrm{Br} \mathrm{J}$ Dermatol 1999;140:273-82. [CrossRef]

24. Kiliç A, Güleç MY, Gül U, Güleç H. Temperament and character profile of patients with psoriasis. J Eur Acad Dermatol Venereol 2008;22:537-42. [CrossRef] 
25. Cloninger CR. A systematic method for clinical description and classification of personality variants. A proposal. Arch Gen Psychiatry 1987;44:573-88. [CrossRef]

26. Gencay-Can A, Can SS. Temperament and character profile of patients with fibromyalgia. Rheumatol Int 2012;32:3957-61. [CrossRef]

27. Boz C, Gazioglu S, Altunayoglu V, Hocaoglu C. Effect of serotonergic antidepressant therapy on temperament and character scales in patients with chronic tension-type headache. Psychiatry Clin Neurosci 2007;61:534-42. [CrossRef]

28. Sasayama D, Hori H, Teraishi T, Hattori K, Ota M, Matsuo J, et al. Difference in Temperament and Character Inventory scores between depressed patients with bipolar II and unipolar major depressive disorders. J Affect Disord 2011;132:319-24. [CrossRef]
29. Brown SL, Svrakic DM, Przybeck TR, Cloninger CR. The relationship of personality to mood and anxiety states: a dimensional approach. J Psychiatr Res 1992;26:197-211. [CrossRef]

30. Svrakic DM, Whitehead C, Przybeck TR, Cloninger CR. Differential diagnosis of personality disorders by the seven-factor model of temperament and character. Arch Gen Psychiatry 1993;50: 991-9. [CrossRef]

31. Jyllhä P, Isometsä P. Temperament, character and symptoms of anxiety and depression in the general population. Eur Psychiatry 2006;21:389-95. [CrossRef]

32. Cloninger CR, Svrakic DM, Przybeck TR. Can personality predict future depression? A twelve-month follow-up of 631 subjects. J Affective Disord 2006;92:35-44. [CrossRef] 